\title{
Atraumatic splenic rupture in a peritoneal dialysis patient
}

\author{
Chiharu Kinoshita ${ }^{1}\left[\right.$ Pham Nguyen Quy $^{2} \cdot$ Masanori Honda $^{3}$
}

Received: 7 September 2017 / Accepted: 22 June 2018 / Published online: 29 June 2018

(C) Japanese Society of Nephrology 2018

\begin{abstract}
Splenic hemorrhage is a potentially life-threatening complication usually occurring after blunt trauma to the abdomen. Atraumatic splenic rupture (ASR) is an uncommon condition, and mostly results from pathology affecting the spleen, such as tumor infiltration or infection. Here, we report a case of atraumatic rupture of a normal spleen in a patient undergoing peritoneal dialysis, and review similar cases in the literature. The case involved a 58-year-old man with nephrotic syndrome who had been undergoing peritoneal dialysis for 1 year. He presented to the hospital with abdominal pain, nausea, and blood-stained dialysate. Laboratory data revealed severe anemia, with a hemoglobin of $4.3 \mathrm{~g} / \mathrm{dL}$. An abdominal computed tomography (CT) scan demonstrated a high-density area around the spleen and malposition of the catheter. Laparoscopy revealed large amounts of coagulated blood surrounding the spleen. The patient was diagnosed with atraumatic splenic bleeding. He improved with bed rest and blood transfusion, and could continue with peritoneal dialysis. It was considered that the etiology of bleeding was directly from the spleen. However, due to the temporary malposition of the peritoneal catheter, catheter-induced splenic trauma could not be ruled out. ASR is a rare entity that needs a high index of suspicion for diagnosis. Using CT scanning and peritoneal fluid analysis, these modalities may assist in the diagnosis. Emergency intervention is required upon definitive diagnosis. Increased awareness of ASR can enhance the early diagnosis and effective treatment.
\end{abstract}

Keywords Atraumatic splenic rupture $\cdot$ Chronic renal failure $\cdot$ Peritoneal dialysis

\section{Introduction}

Splenic hemorrhage is a potentially life-threatening complication usually occurring after blunt trauma to the abdomen. Atraumatic splenic rupture (ASR) is an uncommon condition, and mostly results from pathology affecting the spleen, such as tumor infiltration or infection [1].

Here, we report a case of atraumatic rupture of a normal spleen in a patient undergoing peritoneal dialysis, and review similar cases in the literature.

Chiharu Kinoshita

kinochi3117@gmail.com

1 Department of Nephrology, Kyoto Min-iren Chuo Hospital Japan, 16-1 Nishinokyo Kasuga-cho Nakagyou-ku, Kyoto 604-8453, Japan

2 Department of General Internal Medicine, Kyoto Min-iren Chuo Hospital Japan, Kyoto, Japan

3 Department of Surgery, Kyoto Min-iren Chuo Hospital Japan, Kyoto, Japan

\section{Case report}

A 58-year-old male with end-stage renal disease attributable to nephrotic syndrome, who had been receiving peritoneal dialysis for 15 months, was admitted to our hospital because of abdominal pain, chills, and blood-stained dialysate. $\mathrm{He}$ denied any episodes of trauma, nausea, vomiting, or fever. He had a 4-year history of hypertension for which he took amlodipine $10 \mathrm{mg} /$ day, telmisartan $40 \mathrm{mg} /$ day, nifedipine $20 \mathrm{mg} /$ day, guanabenz $2 \mathrm{mg} / \mathrm{day}$, and furosemide $100 \mathrm{mg} /$ day. Family history and social history were unremarkable.

On a physical examination, the patient was alert, oriented, and cooperative. The body temperature was $36.3^{\circ} \mathrm{C}$ (axilla), the blood pressure was $157 / 103 \mathrm{mmHg}$, the heart rate was 80 beats per minute, regular, the respiratory rate was 16 breaths per minutes, and the oxygen saturation was $97 \%$, while the patient was breathing ambient air. An abdominal examination revealed left upper quadrant abdominal tenderness with rebound tenderness but without guarding. The remainder of the examination was normal.

Laboratory tests (Table 1) revealed a mild anemia with a hemoglobin of $12.0 \mathrm{~g} / \mathrm{dL}$ and a leukocytosis of $14.800 / \mu \mathrm{L}$, 
Table 1 Laboratory data in the first and the second admission

\begin{tabular}{|c|c|c|c|c|c|c|c|}
\hline & First admission & Second admission & Unit & & First admission & $\begin{array}{l}\text { Second } \\
\text { admission }\end{array}$ & Unit \\
\hline WBC & 14,800 & 17,400 & $/ \mu \mathrm{L}$ & $\mathrm{Na}$ & 131 & 130 & $\mathrm{mEq} / \mathrm{L}$ \\
\hline $\mathrm{RBC}$ & $410 \times 10^{4}$ & $249 \times 10^{4}$ & $/ \mu \mathrm{L}$ & $\mathrm{K}$ & 5.6 & 4.5 & $\mathrm{mEq} / \mathrm{L}$ \\
\hline $\mathrm{Hb}$ & 12.0 & 7.6 & $\mathrm{~g} / \mathrm{dL}$ & $\mathrm{Cl}$ & 8.3 & 8.7 & $\mathrm{mEq} / \mathrm{L}$ \\
\hline $\mathrm{Ht}$ & 35.7 & 21.7 & $\%$ & $\mathrm{Ca}$ & 8.3 & 8.7 & $\mathrm{mg} / \mathrm{dL}$ \\
\hline $\mathrm{MCV}$ & 86.8 & 87.1 & $\mathrm{fL}$ & $\mathrm{P}$ & 6.8 & 6.7 & $\mathrm{mg} / \mathrm{dL}$ \\
\hline Plt & $236 \times 10^{4}$ & $26.3 \times 10^{4}$ & $/ \mu \mathrm{L}$ & Glu & 103 & 142 & $\mathrm{mg} / \mathrm{dL}$ \\
\hline PT-INR & 1.01 & 1.13 & & ALT & 12 & 11 & $\mathrm{IU} / \mathrm{L}$ \\
\hline APTT & 28.7 & 29.0 & $\mathrm{sec}$ & AST & 11 & 2 & $\mathrm{IU} / \mathrm{L}$ \\
\hline $\mathrm{Cr}$ & 14.1 & 14.1 & $\mathrm{mg} / \mathrm{dL}$ & LDH & 292 & 162 & $\mathrm{IU} / \mathrm{L}$ \\
\hline BUN & 74.9 & 54.7 & $\mathrm{mg} / \mathrm{dL}$ & ALP & 418 & 354 & $\mathrm{IU} / \mathrm{L}$ \\
\hline $\mathrm{TP}$ & 6.0 & 5.1 & $\mathrm{~g} / \mathrm{dL}$ & CRP & 0.19 & 0.03 & $\mathrm{mg} / \mathrm{dL}$ \\
\hline Alb & 3.5 & 2.9 & $\mathrm{~g} / \mathrm{dL}$ & PCT & NA & $(-)$ & \\
\hline
\end{tabular}

$W B C$ white blood cell count, $R B C$ red blood cell count, $H b$ hemoglobin, $H t$ hematocrit, $M C V$ mean corpuscular volume, Plt platelet, $P T-I N R$ prothrombin time-international normalized ratio, APTT activated partial thromboplastin time, $\mathrm{Cr}$ creatinine, $B U N$ blood urea nitrogen, $T P$ total protein, $A l b$ albumin, $N a$ sodium, $K$ potassium, $\mathrm{Cl}$ chloride, $\mathrm{Ca}$ calcium, $\mathrm{P}$ phosphorus, $\mathrm{Glu}$ glucose, $A L T$ alanine aminotransferase, AST aspartate aminotransferase, $L D H$ lactate dehydrogenase, $A L P$ alkaline phosphatase, CRP C-reactive protein, $P C T$ procalcitonin, NA not available, (-) negative. but a normal C-reactive protein level of $0.19 \mathrm{mg} / \mathrm{dL}$. Blood urea nitrogen (BUN) was $74.9 \mathrm{mg} / \mathrm{dL}$ and creatinine was $14.12 \mathrm{mg} / \mathrm{dL}$. Coagulation studies were normal. Fecal occult blood testing of his stool was negative. Peritoneal fluid analysis showed a white cell count of $167 / \mu \mathrm{L}$, with a neutrophil predominance $(89 \%)$, consistent with peritoneal infection. No bacteria were visualized on Gram-stain examination of the fluid. A non-contrast abdominal computed tomography (CT) scan was performed which revealed some mild ascites but no splenomegaly, displacement of the Tenckhoff dialysis catheter, or other specific findings.

As a result, the patient was hospitalized for observation. Intraperitoneal administration of cefazolin $1 \mathrm{~g}$ and ceftazidime $1 \mathrm{~g}$ was started, and his symptoms resolved after $24 \mathrm{~h}$. The blood-stained dialysate improved after 6 days. Although culture of the peritoneal fluid revealed no growth, antibiotics were continued for 2 weeks for peritoneal dialysis-associated peritonitis. Since the hemoglobin level was decreased to $8.5 \mathrm{~g} / \mathrm{dL}$ and recovered slowly with antibiotic therapy, we thought that anemia might be due to inflammation and chose watchful waiting. The patient was discharged with a hemoglobin level of $9.2 \mathrm{~g} / \mathrm{dL}$ at day 17 after admission.

However, 3 days post-discharge, he was readmitted because of recurrent abdominal pain and blood-stained peritoneal dialysate. There were no episodes of trauma, injury, vomiting, or coughing in the preceding days before readmission. On the admission day, his body temperature was $36.8^{\circ} \mathrm{C}$ (axilla), the blood pressure was $149 / 96 \mathrm{mmHg}$, and the heart rate was regular at 80 beats per minute. The respiratory rate was 18 breaths per minutes and the oxygen saturation was $97 \%$ breathing ambient air. An abdominal examination revealed similar findings as originally found during the previous admission, including normal bowel sounds, and focal tenderness in the left upper quadrant with rebound.

Laboratory test results (Table 1) showed a worsening anemia with a hemoglobin of $7.6 \mathrm{~g} / \mathrm{dL}$, a hematocrit $21.7 \%$, and a leukocytosis of $17.400 / \mu \mathrm{L}$, but with a normal C-reactive protein level of $0.03 \mathrm{mg} / \mathrm{dL}$. The BUN was $54.7 \mathrm{mg} / \mathrm{dL}$ and the creatinine was $14.06 \mathrm{mg} / \mathrm{dL}$. Coagulation studies were normal. A Gram-stain of the peritoneal fluid was significant for the presence of 390 cells/ $\mu \mathrm{L}$ (neutrophil count $88 \%$ ). Bacteria were absent on Gram-stain, as was subsequent culture of the peritoneal fluid. However, thrombi were found in dialysate, leading to catheter obstruction. A plain abdominal radiograph revealed catheter tip migration out of the pelvis to the left hypochondrium (Fig. 1a). We repeated an abdominal CT scan and found a perisplenic hematoma associated with a moderate amount of high-density fluid in the peritoneal cavity (Fig. 1b).

Recurrent peritonitis was suspected and intraperitoneal antibiotics of an exact combination to the initial admission were resumed. Again, the blood-stained dialysate improved over several days, so the patient was treated with conservative medical therapy. However, on the 13th day of hospitalization, blood-stained dialysate was reported for a third time. Since the patient's anemia rapidly progressed with a drop of the hemoglobin level to $4.3 \mathrm{~g} / \mathrm{dL}$, a total of six units of packed red cells were transfused. An exploratory laparoscopy was performed and identified a large perisplenic hematoma with no signs of active bleeding or omental bleeding (Fig. 2). We could not further examine the surface of 

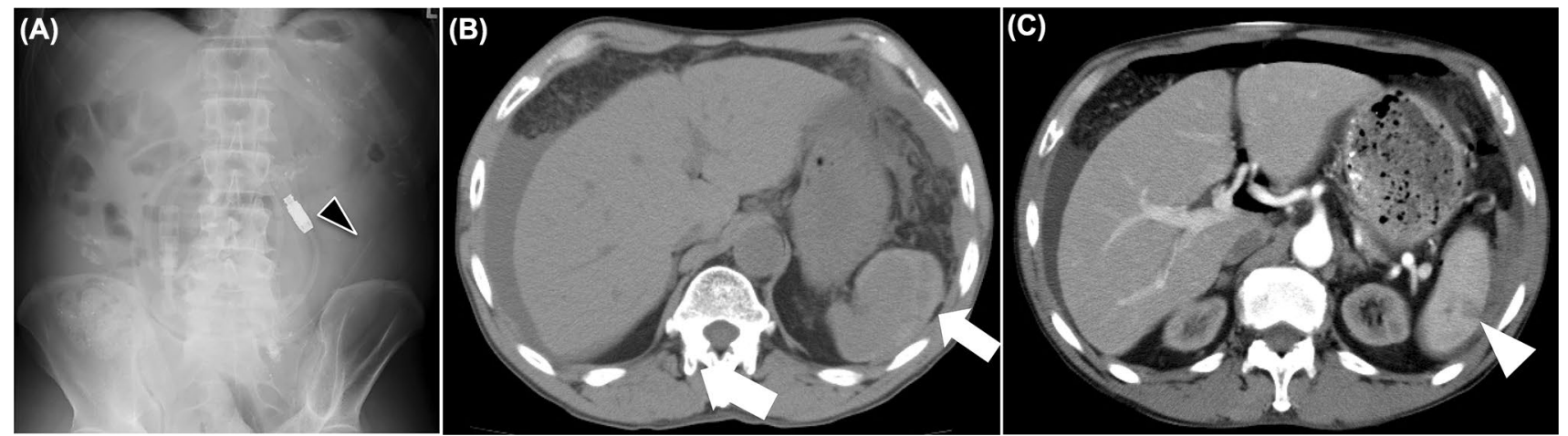

Fig. 1 Displacement of the catheter tip and splenic rupture on imaging studies. a Radiograph of the abdomen captured catheter tip migration to the left hypochondrium (black arrow head).b Non-contrast CT scan revealed a perisplenic hematoma (white arrow) associ-

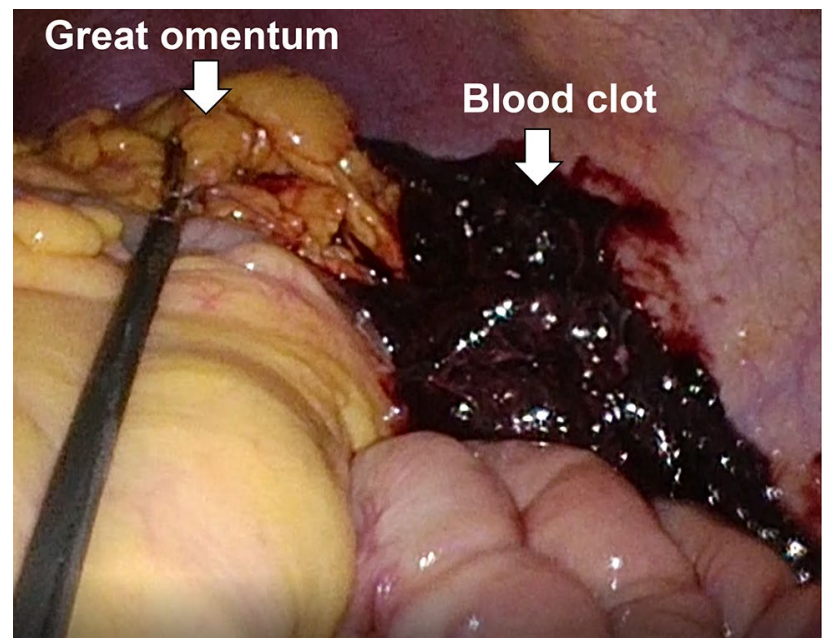

Fig. 2 Exploratory laparoscopy revealing a large perisplenic hematoma without signs of active bleeding. The surface of the spleen was not investigated since it was covered by the blood clots

the spleen, since removing the hematoma might cause rebleeding. Although the catheter tip was back to its usual position and we confirmed intraoperatively that it had not reached the spleen, a peritoneal wall anchor technique was done to definitively improve peritoneal catheter fixation. The patient did well postoperatively with improvement of the peritoneal dialysate.

Three days after the operation, an abdominal contrast CT scan was performed to rule out the possibility of splenic artery pseudoaneurysm. Linear hypodense areas consistent with lacerations in the spleen were observed (Fig. 1c) as an evidence to support the diagnosis of splenic rupture (Grade II). Delayed rupture was unlikely, since his hemoglobin increased to $11.1 \mathrm{~g} / \mathrm{dL}$ without blood transfusion.

To evaluate the major causes of ASR, several serum markers were measured. Epstein-Barr virus anti-viral ated with a moderate amount of high density fluid in the peritoneal cavity.c Contrast CT scan showed a hypodense area consistent with lacerations in the spleen (white arrow head)

capsid antigen IgM was negative, and cytomegalovirus C7 HRP was also negative. Although an initial soluble interleukin-2 receptor level was $1400 \mathrm{U} / \mathrm{mL}$, this value normalized in a subsequent measurement. The level of M-protein was not elevated. Together with negative findings on physical examination and radiographic evaluation, infectious mononucleosis, cytomegalovirus, malignant lymphoma, and multiple myeloma were considered unlikely. Repeated and extended cultures of the peritoneal dialysate were negative for tuberculosis or fungal infection. Cytology examination of the ascites was also unrevealing. The patient resumed to his ordinary peritoneal dialysis with no reported recurrence after 20 months of follow-up.

\section{Discussion}

Splenic rupture typically presents with left upper quadrant abdominal tenderness with or without distention, syncope, and/or a decrease in systemic blood pressure. Although the diagnosis is often established with abdominal ultrasonography or CT imaging [2], determining the etiology is more difficult. Splenic rupture often occurs in association with trauma, but it may also occur due to atraumatic causes.

Criteria to diagnose atraumatic rupture of the spleen were suggested by Orloff, Peskins, and other authors since 1958 $[1,3,4]$. In this case, the diagnosis of ASR was considered, because (1) a thorough history revealed no antecedent trauma, (2) no organs other than the spleen was seen to have ruptured by exploratory operation, (3) no perisplenic adhesions were found to be consistent with trauma or a previous rupture, (4) and the spleen was normal on gross examination.

A recent systematic review classified the causes of ASR into six main categories as follows: neoplastic (30.3\%), infectious $(27.3 \%)$, non-infectious inflammatory (20.0\%), 
Table 2 Major causes of atraumatic splenic rupture

\begin{tabular}{l} 
Neoplastic disorders \\
Leukemia \\
Lymphoma \\
Myeloproliferative disorders \\
Myelodysplastic syndromes \\
Angiosarcoma \\
Infectious disorders \\
Infectious mononucleosis \\
Cytomegalovirus infection \\
Human immunodeficiency virus infection \\
Dengue fever \\
Endocarditis \\
Tuberculosis \\
Typhoid fever \\
Malaria \\
Non-infectious inflammatory disorders \\
Pancreatitis \\
Amyloidosis \\
Rheumatoid arthritis \\
Systemic lupus erythematodes \\
Granulomatosis with polyangiitis \\
Polyarteritis nodosa \\
Antrogenic disorders \\
Thrombolytic therapy \\
Granulocyte colony-stimulating factor \\
Dialysis \\
Mechanical disorders \\
Pregnancy \\
Idiopathic (normal spleen) \\
\hline
\end{tabular}

iatrogenic $(9.2 \%)$, mechanical disorders $(6.8 \%)$, and idiopathic $(6.4 \%)$ (Table 2) [1, 3].

Aubrey-Bassler et al. identified 112 cases of ASR occurred after medical procedures [5], among which one case was attributed to the displacement of a continuous ambulatory peritoneal dialysis catheter [6]. From 1986 to 2016, a total of eight cases of ASR had been reported in patients undergoing peritoneal dialysis (Table 3) [6-12]. Among these, three cases were due to amyloidosis: one case was caused by splenic infarction and another case was secondary to chronic myelogenous leukemia. The remaining two cases did not describe any obvious disorders in the spleen.

In one case, splenectomy was performed and a pathological examination revealed many lacerations on the surface of the spleen [6]. The patient had worked for many hours using a manual sewing machine. Since flexing and extending the legs may affect intra-abdominal pressure, the author concluded that the catheter tip might have been intermittently thrust into the spleen, which is a mobile organ. This is the only case that described the involvement of catheter displacement. In another case, a pathological examination was not performed, but the patient did not have apparent underlying diseases such as a blood dyscrasia, malignancy, infectious mononucleosis, or cytomegalovirus infection [12]. The author considered the potential involvement of antiplatelet agents along with increased intra-abdominal pressure by the peritoneal dialysate, along with vomiting.

In this case, we could not identify any potential causes such as a coagulopathy, malignancy, infectious diseases, or other abnormalities related to the spleen. Although we could not analyze the spleen for microscopic alterations, a previous echocardiographic examination and endoscopic biopsy of the stomach did not support the possibility of amyloidosis. Because the catheter tip migrated out of the pelvis to the left hypochondrium and then backed to its usual position during the second admission, we considered it as a possible cause of the perisplenic hematoma. Although we confirmed intraoperatively, in a supine position, that the catheter tip could not have reached the surface of the spleen, we could not evaluate this spatial relationship in other body positions.

Concerning the prognosis of this rare phenomenon, six of the seven reported cases needed splenectomy, and five patients could resume peritoneal dialysis. In our case, the hemorrhage improved by conservative treatment alone, the catheter was preserved, and the patient could continue his regular peritoneal dialysis.

\section{Conclusion}

ASR can be observed in peritoneal dialysis patients, although it is a very rare complication. An early diagnosis may lead to a better outcome as shown in this case. Our patient improved by conservative treatment alone and could continue the peritoneal dialysis with no recurrence after 20 months of follow-up. 
Table 3 Atraumatic splenic rupture in peritoneal dialysis patients

\begin{tabular}{|c|c|c|c|c|c|c|c|c|}
\hline Case & 1 & 2 & 3 & 4 & 5 & 6 & 7 & Our case \\
\hline Sex & Male & Female & Male & Female & Male & Female & Male & Male \\
\hline Age (years) & 68 & 67 & 44 & 74 & 43 & 44 & 56 & 58 \\
\hline $\begin{array}{l}\text { Time on dialy- } \\
\text { sis (months) }\end{array}$ & 18 & 3 & 84 & 3 & 41 & 20 & 60 & 15 \\
\hline Case of ESRD & $\mathrm{DM}$ & Amyloidosis & $\mathrm{CGN}$ & Amyloidosis & Amyloidosis & HT & CGN & CGN \\
\hline Trigger & $\begin{array}{l}\text { Splenic infarc- } \\
\text { tion }\end{array}$ & No & No & No & No & No & Vomiting & No \\
\hline Presentation & Kehr's sign & Kehr's sign & Vomiting & $\begin{array}{l}\text { Abdominal } \\
\text { pain }\end{array}$ & Kehr's sign & $\begin{array}{l}\text { Upper } \\
\text { left-sided } \\
\text { abdominal } \\
\text { pain }\end{array}$ & $\begin{array}{l}\text { Upper } \\
\text { left-sided } \\
\text { abdominal } \\
\text { pain }\end{array}$ & $\begin{array}{l}\text { Upper left-sided } \\
\text { abdominal } \\
\text { pain }\end{array}$ \\
\hline $\begin{array}{r}\text { Diagnostic } \\
\text { approach }\end{array}$ & Laparotomy & Laparotomy & CT & Laparoscopy & Laparoscopy & Laparotomy & CT & Laparoscopy \\
\hline Management & Splenectomy & Splenectomy & Splenectomy & Splenectomy & Splenectomy & Splenectomy & Conservative & Conservative \\
\hline $\begin{array}{l}\text { Spleen pathol- } \\
\text { ogy }\end{array}$ & $\begin{array}{l}\text { Splenic infarc- } \\
\text { tion }\end{array}$ & Amyloidosis & CML & $\begin{array}{l}\text { Amyloid angi- } \\
\text { opathy }\end{array}$ & Amyloidosis & Normal & Normal & Normal \\
\hline $\begin{array}{l}\text { Evolution } \\
\text { References }\end{array}$ & $\begin{array}{l}\text { Survival } \\
\text { [7] }\end{array}$ & $\begin{array}{l}\text { Survival } \\
{[8]}\end{array}$ & $\begin{array}{l}\text { Survival } \\
\text { [9] }\end{array}$ & $\begin{array}{l}\text { Survival } \\
{[10]}\end{array}$ & $\begin{array}{l}\text { Survival } \\
{[11]}\end{array}$ & $\begin{array}{l}\text { Survival } \\
{[6]}\end{array}$ & $\begin{array}{l}\text { Survival } \\
{[12]}\end{array}$ & Survival \\
\hline
\end{tabular}

\section{Compliance with ethical standards}

Conflict of interest The authors have declared that no conflict of interest exists.

Human and animal rights statement This article does not describe any studies with human participants performed by any of the authors.

Informed consent Informed consent was obtained from all individual participants included in the study.

\section{References}

1. Renzulli P, Hostettler A, Schoepfer AM, Gloor B, Candinas D. Systematic review of atraumatic splenic rupture. Br J Surg. 2009;96:1114-21.

2. Alabousi A, Patlas MN, Scaglione M, Romano L, Soto JA. Crosssectional imaging of nontraumatic emergencies of the spleen. Curr Probl Diagn Radiol. 2014;43:254-67.

3. Debnath D, Valerio D. Atraumatic rupture of the spleen in adults. J R Coll Surg Edinb. 2002;47:437-45.

4. Orloff MJ, Peskin GW. Spontaneous rupture of the normal spleen: a surgical enigma. Int Abstr Surg. 1958;106:1-11.
5. Aubrey-Bassler FK, Sowers N. 613 cases of splenic rupture without risk factors or previously diagnosed disease: a systematic review. BMC Emerg Med. 2012;12:11.

6. de Los Santos CA. von Eye O, d'Avila DO, Mottin CC. Rupture of the spleen: a complication of continuous ambulatory peritoneal dialysis. Perit Dial Int. 1986;6:203-4.

7. Kanagasundaram NS, Macdougall IC, Turney JH. Massive haemoperitoneum due to rupture of splenic infarct during CAPD. Nephrol Dial Transplant. 1998;13:2380-1.

8. Russell TJ, Ferrera PC. Spontaneous rupture of an amyloid spleen in a patient on continuous ambulatory peritoneal dialysis. Am J Emerg Med. 1998;16:279-80.

9. Wang JY, Lin YF, Lin SH, Tsao TY, Wang JY, et al. Hemoperitoneum due to splenic rupture in a CAPD patient with chronic myelogenous leukemia. Perit Dial Int. 1998;18:334-7.

10. Chau EM, Chan AC, Chan WK. Spontaneous atraumatic rupture of a normal-sized spleen due to AL amyloid angiopathy. Amyloid. 2008;15:213-5.

11. Piotti G, Filippin F, Rampino T, Bedino G, Bosio F, Morbini $\mathrm{P}$, et al. Atraumatic spleen rupture in dialyzed patients: clinical report and review of the literature. Perit Dial Int. 2011;31:486-92.

12. Yamamoto M, Sakurada T, Uehara K, Shibagaki Y. Bloody peritoneal dialysate due to non-traumatic splenic rupture in a patient on peritoneal dialysis. J Jpn Soc Dial Ther. 2016;49:605-9. 